\title{
GOYA DEPOIS DE GOYA
}

\section{Dennis Radünz UFSC}

RESUMO: 0 procedimento de montagem do poema "Goya después de El Prado", de Hebert Benítez, atualiza a Gravura \# 43 de Francisco de Goya e, atravessado de heterocronia, incita a uma leitura do "princípio-atlas" (Georges Didi-Huberman) e da configuraccão do monstro como compossibilidade e mistura, desde a filosofia pré-socrática de Empédocles de Agrigento. A atribuição de valor, a causalidade, a periodização e, em especial, a heterocronia são substratos dessa cena de leitura que procura articular a gravura de 1799 e 0 poema de 1999 à noção de "desativação da autonomia" (Raúl Antelo) e, no percurso, encontra a heterocronia e a montagem da artista Leila Danziger, em sua exposição "Navio de emigrantes" (2018/2019).

PALAVRAS-CHAVE: Francisco de Goya; Hebert Benítez; Heterocronia.

\section{GOYA AFTER GOYA}

ABSTRACT: The assembly procedure of the poem "Goya después de El Prado", by Hebert Benítez, updates Francisco de Goya's Engraving \# 43 and, through heterocrony, incites a reading of the "principle-atlas" (Georges Didi-Huberman) and the configuration of the monster as compossibility and mixture, from the pre-Socratic philosophy of Empedocles of Agrigento. The attribution of value, causality, periodization and, in particular, heterocrony are substrata of this reading scene that seeks to articulate the 1799 engraving and the 1999 poem to the notion of "deactivation of autonomy" (Raúl Antelo) and, on course, finds the heterochrony and the assembly of the artist Leila Danziger, in his exhibition "Navio de emigrantes" (2018/2019).

KEYWORDS: Francisco de Goya; Hebert Benítez; Heterocrony.

Dennis Radünz é escritor, editor e mestre em Literatura no Programa de Pós-graduação em Literatura da Universidade Federal de Santa Catarina. 


\title{
GOYA DEPOIS DE GOYA
}

\section{Dennis Radünz}

Três horas no Museu do Prado, Madri, o transcurso previsto por Eugênio D'Ors para atravessar, naquele "sin par museo", toda a coleção das constantes artísticas e dos éons... e voltar para contemplar Correggio ${ }^{1}$. Mas um corte no tempo estético pede a dissecção da prancha 43 dos Caprichos de Francisco de Goya em uma outra cena, no decurso de dois séculos, e no "contratempo" de outra época, como nos invita o poema "Goya después de El Prado":

\author{
el monstruo fecunda trozos varios de razón en sueños \\ el mar es una cinta líquida \\ encinta la palabra el horizonte de fracturas \\ mediante aguas fugadas del cuerpo cuajado por islotes \\ sin pronunciación un ominoso estremecer \\ de las partes (ese viento resbaloso \\ entre carnes como loca estampida de palabras) \\ tales partes asaltadas por murciélagos búhos con felinos \\ pero el sueño de la razón no causa monstruos \\ ellos ya estaban cultivaban en procreación \\ la cordura el corazón de las famílias \\ las herencias reflexivas emociones crecen tíbias \\ hijas de los monstruos padres tanta danza atada \\ al único cordón en el principio hay monstruo nada más \\ los sueños de la razón no engendran monstruos \\ ellos navegaban diestramente no son crueles \\ pernoctaban plenos \\ de comercio con la muerte \\ los monstruos viajan colmados de semen el deseo \\ de la gente se desplanta en óvulos tremendos \\ los sueños de la razón engendraron sueños \\ morir dormir venir del monstruo es un destino practicable \\ en maletines logaritmos ensayos bolsillos bolsas con comidas \\ hacen lo suyo: alimentan acrecientan riegan con su fe \\ sus propias galerías las inepcias que permiten \\ creer que con deslices la razón da luz a monstruos \\ goya supo lo que dijo y nadie sabe lo que ve: \\ que la razón es un sueño y no otra cosa \\ (...)
}

${ }^{1}$ D'ORS, Eugenio. En el Prado otra vez. El noli mi tangere de Correggio. In: Lo barroco. Edición preparada por Ángel D'Ors e Alicia García Navarro de D’Ors. Madrid: Editorial Tecnos / Alianza, 2002. p. 117-118. 
Desde o primeiro verso, "el monstruo fecunda trozos varios de razón en sueños", o poema "Goya después de El Prado", de Hebert Benítez (Montevideo, 1960) - compilado por Rafael Courtoisie no livro Poesia Uruguaya: Antología Esencial $^{2}$ - inventaria (ou aparenta inventariar) um atlas sucinto das questões da periodização, da causalidade, do heterocronismo e da atribuição de valor: aqui, estamos ainda diante de um Francisco de Goya, mas "depois" do Museu do Prado.

Na repetição diferida, os "vários pedaços" (que são frações, intervalos e extratos e, ao mesmo tempo, nonadas e troços) instauram as compossibilidades fecundadas pelo fictum do sono/do sonho. Os troços vários de razão: avarias. E o poema "Goya..." plagia os procedimentos de enquadramento e de montagem lidos por Didi-Huberman no atlas ${ }^{3}$ de Aby Warburg - um painel móvel.

Fora dos lindes do tempo histórico, e nos limbos do tempo estético, esse poema inscreve os seus traços em uma leitura não ecfrástica da célebre prancha goyesca e, nessa desmedida dos tempos e contratempos que incidem desde 1797-1799 sobre a aquatinta, o quadro (tableau) sai "da unidade visual e da imobilidade temporal" " 4 e volve à mesa de operação (table). O estranhamento da cena - partes asaltadas por murciélagos búhos con felinos - torna à legibilidade em uma emergência de anáfora ("pero el sueño de la razón no causa monstruos // los sueños de la razón no engendran monstruos // los sueños de la razón engendraron sueños") e avança na seriação dedutiva, até a conclusão gongórica ou conceptista: "la razón es un sueño y no otra cosa". Aquela sentença impressa - "o sonho da razão produz monstros" - se dissemina e decuplica na recursividade, à maneira contemporânea, o que não significa soma, e sim uma pletora de relações, pondo todo o Goya, 'depois' do Museu do Prado, de novo em movimento.

Na mesma figura da fixidez do mito de Atlas lido por Didi-Huberman, Gonçalo Tavares enuncia, em Atlas do corpo e da imaginação, o problema do inamovível (ou do cânone, ou do monumento, ou da série filológica). No verbete "imobilidade: museu" postula:

\footnotetext{
${ }^{2}$ BENIITEZ, Hebert. Goya después de El Prado. In: COURTOISIE, Rafael (Org.). Poesía uruguaya: antología esencial. Madrid: Visor Libros, 2010. (La Estafeta del Viento / Colección Visor de Poesia), p. 393-396.

3 "Atlas seria a figura emblemática [mitológica e epistemológica] de uma polaridade fundamental através da qual Warburg nunca deixou de pensar a história das civilizações mediterrâneas: de um lado, a tragédia pela qual toda cultura exibe seus próprios monstros (monstra); de outro, o saber pelo qual toda cultura explica, redime ou engana esses mesmos monstros na esfera do pensamento (astra)." DIDI-HUBERMAN, Georges. Atlas, ou o gaio saber inquieto (O olho da história, III). Tradução de Márcia Arbex e Vera Casa Nova. Belo Horizonte: Editora UFMG, 2018, p. 94-95.

${ }^{4}$ Ibidem, p. 67.
} 
A imobilidade é não sair da posição anterior, trata-se de uma ligação fixa, não desejada, ligação ao passado. Diríamos mesmo que, em termos de movimento, a imobilidade é a manifestação de um excesso de memória corporal, de uma memória que não permite que o corpo avance, que o corpo se torne presente, novidade. A imobilidade física não é ausência de movimento, mas fixação - transformação do movimento no seu oposto como no conceito de museu: tempo guardável, pois, como uma joia, como qualquer coisa que ocupe espaço, volume, este é o tempo fixado, tempo perversamente tornado contemplável, movimento - também ele - que se pode contemplar uma e outra vez: eis a imobilidade. A imobilidade é, ainda, voltando à análise dos versos aforísticos de Nietzsche, um excesso de pensamento sobre o que fazer a seguir. A imobilidade face a uma encosta existe quando o corpo está centrado na pergunta: "Como é que se deve atacar a encosta?" Eis, pois, que a compreensão do que se vai fazer se torna um obstáculo. Compreender é não subir. Subir é compreender durante o movimento. ${ }^{5}$

Nessa translação metafórica, o poema de Benítez "sobe a encosta" do Museo del Prado e, por essa imagem, liberta aquele corpo sonado e recurvado sobre a mesa do seu excesso de passado. Pela mesma metáfora, o poema parecer tirar aquele Goya do templum (da contemplação), i.é., muda-o de posição.

Assim, esse poema publicado em $1999^{6}$ "desativa a autonomia" 7, nos termos de Raúl Antelo, do estado museológico (herdade de Mausolo) da Gravura 43 e situa Francisco de Goya depois e desmembrado do corpo Museu do Prado. E o que essa nova situação engendra? Abolida a sintaxe, esse 'depois', advérbio de lugar e de tempo, fecunda os troços vários (e não vários troços) de espaço-tempo; fora da ordem do discurso canônica museológica, derrui a periodização da história da arte em troços-vários-de-razão - faz heterocronia.

Em outra direção, se lidos a contrapelo da figura 'monstruosa' de Febrônio Índio do Brasil - um objeto da citada leitura de Antelo -, esses monstros que "[...] ya estaban cultivaban en procreación / la cordura el corazón de las famílias / las herencias reflexivas emociones crecen tíbias / hijas de los monstruos padres tanta danza atada / al único cordón en el principio hay monstruo nada más" parecem consumar a tragédia das heranças, das corduras e famílias que descendem da deformidade "desde o princípio" - é a tragédia "os bens e o sangue" - e, nessa pregnância de origem, apontam a um mito de destinação

${ }^{5}$ TAVARES, Gonçalo M. Atlas do corpo e da imaginação: teoria, fragmentos e imagens. Alfragide (Portugal): Editorial Caminho, 2013, p. 244-245.

${ }^{6}$ Publicado no Boletín de la Academia Nacional de Letras: Tercera época, n. 5, 1999, p. $127-$ 128.

7 No ensaio "Carl Einstein, desativar a autonomia", Raúl Antelo evoca o 'princípio-atlas' de Negerplastik e de Documents, e aduz Blaise Cendrars e Osório César, para compor o campo de forças ainda em ato que, em minha hipótese, permite ler a 'deformidade' da Gravura 43 também como um "estranho realismo subjetivado". PETERLE, Patricia; SANTURBANO, Andrea; BARBOSA, Maria Aparecida (Org.). Coleções literárias. Rio de Janeiro: 7 Letras, 2014, p. 39. 
que deve engendrar os novos monstra (com a dança atada e filhas de pais-monstro), como se a imagem de 1799 figurasse, agora, outro caso cotidiano da crônica policial, ou volvesse às páginas de literatura penal. Segunda hipótese de heterocronia.

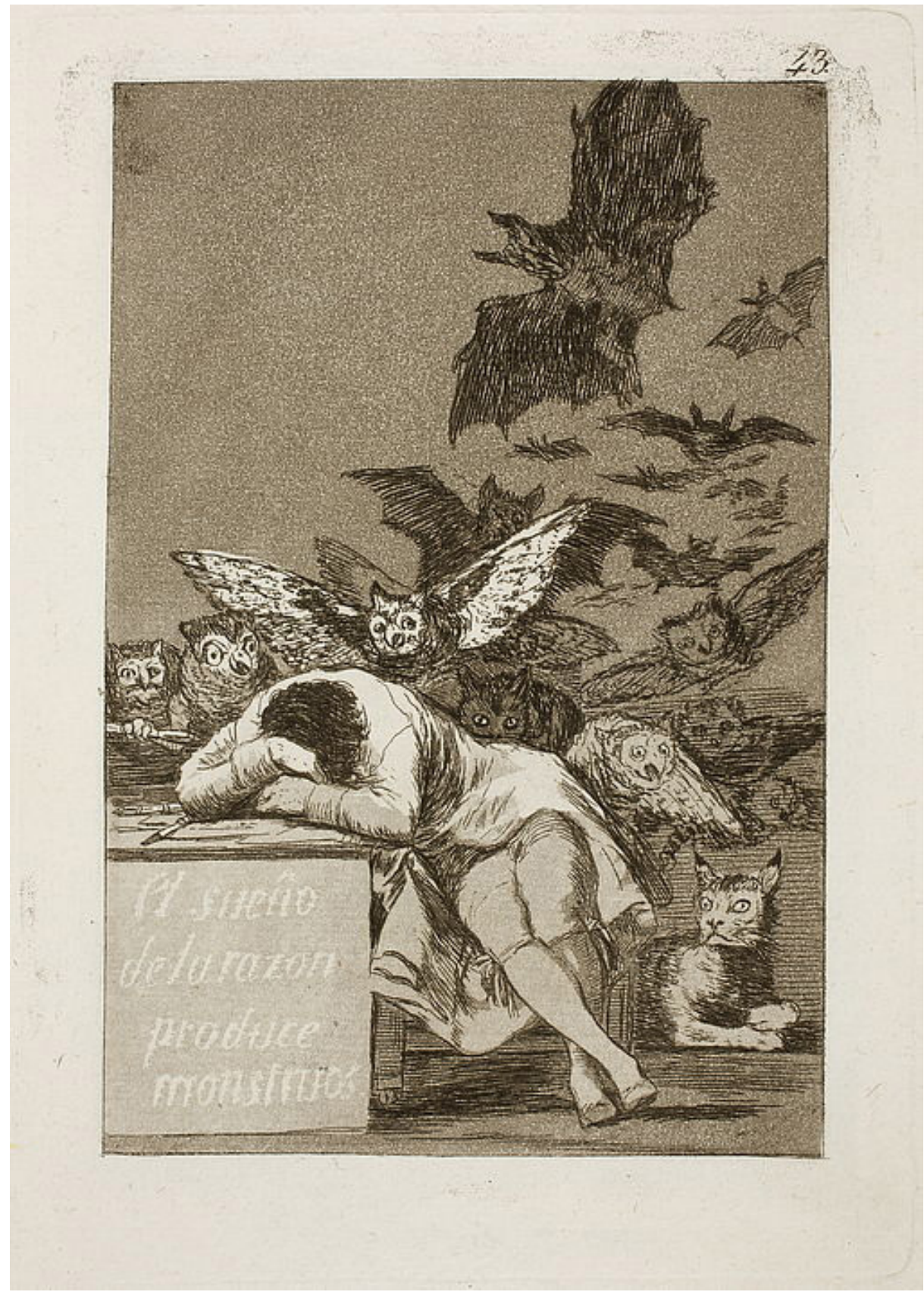

FRANCISCO DE GOYA - El sueño de la razón produce monstruos (1797-1799). Da série "Caprichos" (estampa), 43. Primeira edição, Madri, 1799. Técnica: gravura e aquatinta s/ papel. Dimensões: 213 x 151 mm [folha] / 306 × 201 mm [papel]. Acervo da Coleção Plácido Arango, Museo del Prado, $1991 .{ }^{8}$

${ }^{8}$ Cf. GOYA EN EL PRADO. Disponível em: https://www.goyaenelprado.es/inicio. Acesso em: 10. fev, 2019. 
Todavia, na direção reversa da leitura episódica do poema como cena do crime, porque sonhos da razão têm produzido sem cessar estados de exceção e monstruosidades, e também sem incorrer na paráfrase de "Goya después de El Prado", tomemos seu verso "sin pronunciación un ominoso estremecer de partes" como o sinal (ou sintoma) do procedimento experimental de engendramento da deformidade na cena fixa, ou seja, o monstruo deriva da sutura entre as partes incôngruas, e troços vários de razão fecundam-no no "estremecer das partes", ao modo de Bataille, numa potência do informe. Nesse sentido, na partição de si, produto de arte combinatória, o monstro é uma montagem.

Assim, rompendo-se os cercos da causalidade e da atribuiç̧ão de valor, podemos fazer derivar o poema recursivo do Uruguay de toda uma "física" da Antiguidade pré-socrática. Rememoremos aqui a 'zoogonia' de Empédocles de Agrigento, em "Da Natureza”, e sua formulação, comentada por Écio, da teoria da evolução como "mistura":

[...] Empédocles sustentou que as primeiras gerações de animais e plantas não eram completas, mas consistiam de membros independentes, não ligados entre si; as segundas gerações, surgidas da junção destes membros, eram como seres oníricos; a terceira foi a geração das formas totalmente constituídas; e a quarta já não provinha das substâncias homogêneas, tais como a terra e a água, mas devido a uma mistura, resultante, nuns casos, da condensação dos seus alimentos, noutros, porque a beleza feminina excitou o desejo sexual; e as diversas espécies de animais distinguiram-se pela qualidade da mistura nelas verificada... ${ }^{9}$

Comentando essa tese da mistura, Simplício sustenta em De caelo (587, 18-19): "Aqui brotaram numerosos rostos sem pescoços, errantes andavam braços soltos, sem ombros, e olhos vagueavam sozinhos, carecidos de testas"10. Outro comentador, Eliano, sumaria em A natureza dos animais (XVI, 29) a proposição da geração de 'híbridos' de Empédocles - "diferentes na combinação de suas formas, mas interligados pela unidade de seus corpos" -, descrevendo as ocorrências dos térata nesses termos:

Muitos nasceram com duas cabeças e duplo torso - bois com feições humanas surgiram e, inversamente, homens de feições bovinas - criaturas misturadas, parte com formas masculinas, parte com formas femininas providas de sinistros genitais. ${ }^{11}$

\footnotetext{
${ }_{9}$ KIRK, Geoffrey S.; RAVEN, John Earle; SCHOFIELD, Malcolm. Os filósofos pré-socráticos: história crítica com selecção de textos. 4. ed. Tradução de Carlos Alberto Louro Fonseca. Lisboa: Fundação Calouste Gulbenkian, 1994. p, 317.

10 Ibidem, p. 318.

${ }^{11}$ BARNES, Jonathan. Filósofos pré-socráticos. Tradução de Julio Fischer. São Paulo: Martins Fontes, 1997. P, 211.
} 
Despedidas dos astra do plano das Ideias, a evolução das formas vivas e impuras no plano dos monstra necessita uma visada dadaísta, porque o pesadelo da razão - a ratio da taxonomia que fixa a forma dos corpos - não invalida a teratologia de todas as combinações particulares e provisórias na remontagem dos espécimes; como o diz Michel Serres, em Atlas: "a vida longa das espécies passa por seres vivos breves". ${ }^{12}$

Em outras palavras, fora da fábula do Uno (a divindade, razão, Estadonação), tudo é monstra, e o poema de Hebert Benítez é uma espécie de canto paralelo (paródia) que instaura uma "terça área" nessa cena de leitura, enquanto movimenta a Gravura 43 de Goya, porque a desmembra e recombina-a. Abre-a de novo à mistura: produz monstro. Na copiosa carnação dos monstra na arte moderna e nas vanguardas, uma obra "menor" de Max Ernst - "La chambre à coucher de max ernst cela vaut la peine d'y passer une nuit" (1920) - afronta o logos com a eidôla de uma ovelha, um urso, uma baleia, morcego, peixe e serpente em um quartinho de dormir, mas com todo "despedaçamento da extensão" do templum diminuto que reúne os disparates das ordens do reino animal, dos tamanhos e das proporções, no mesmo ritmo de "iminência" e de ameaça que há em "El sueño de la razón produce monstruos". É a constante do tropo da desproporção.

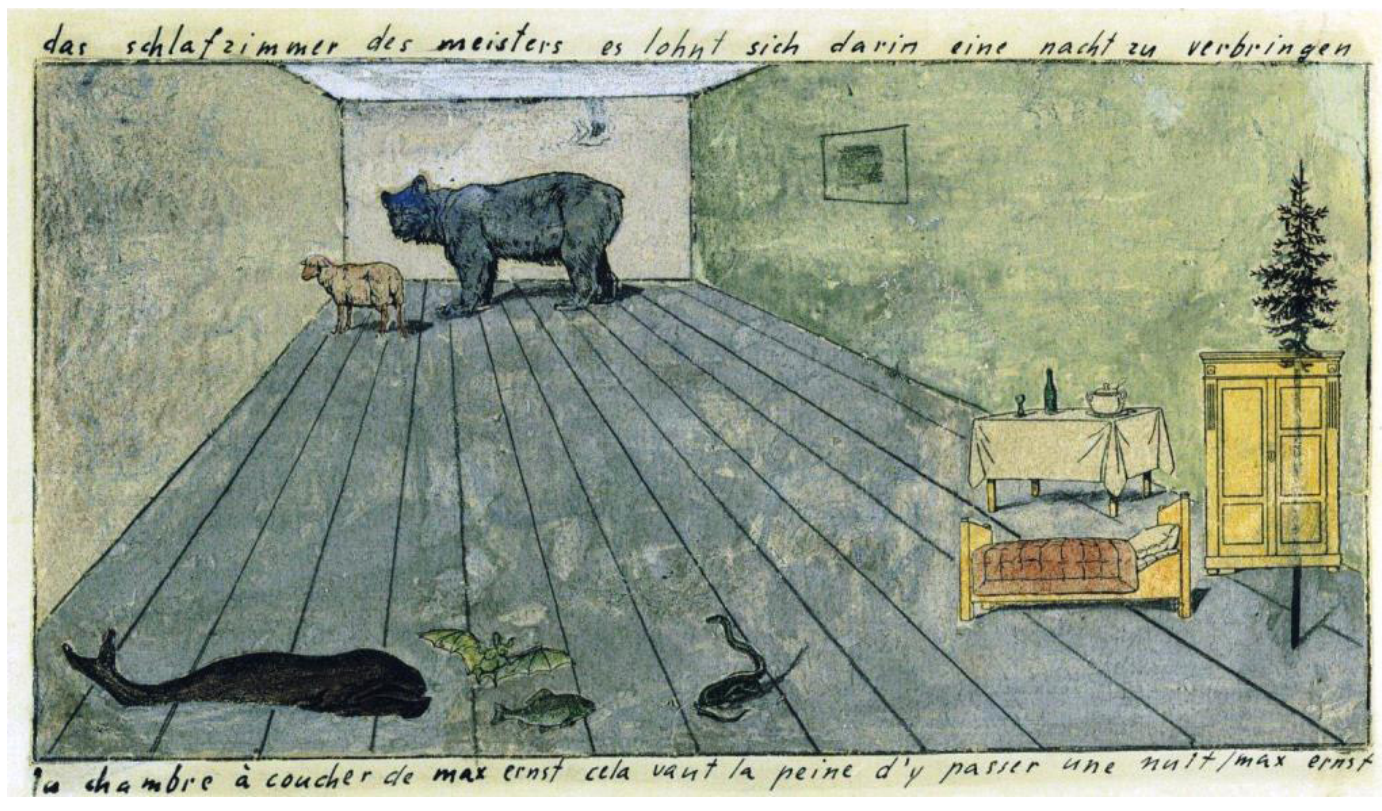

MAX ERNST. "La chambre à coucher de max ernst cela vaut la peine d'y passer une nuit" (1920). colagem, guache e lápis sobre papel, de 16,3 x 22cm., Coleção Werner Schindler, Zurique.

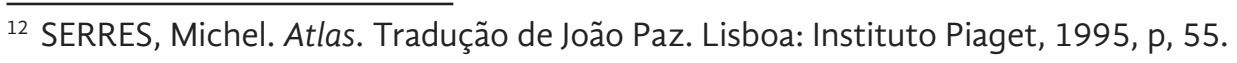


Outro vasto sonho da razão, a Amazônia, produziria, segundo Benjamin Péret, o "inacabamento" e a deformidade da obra de Maria Martins (aproximando-a da pantera com pele de homem que Rimbaud divisou, com a razão em sonho, em Le bateau ivre):

[...] Basta sobrevoar o curso do Amazonas para logo convencer-se de que os quatro elementos dos Antigos [...] permaneceram inextricavelmente misturados em uniões monstruosas e febris, cujo resultado se mantém imprevisível. ${ }^{13}$

Trouxe Max Ernst e Marta Martins à table, mas a própria quête do 'princípio-atlas' é o inumerável e as suas relações, bastando citar a miríade de landscapes, seascapes, cities, still lifes, Hitler e Holocausto que Gerard Richter compilou e "confinou", de 1962 a 2006, nas sucessivas edições de Atlas: mapas de ideias, processos, vida e tempos. ${ }^{14}$ Pois 'relações incomensuráveis' entre signos (sémeia), imagens ( $p$ hasma) e monstruosidades (térata) ${ }^{15}$ são acionadas pelas mãos do arúspice (ou colecionador, montador), que intervém, engendrando manufatura: pro ductio. Ele é munido de "partes mágicas", como diz a 'zoofonia' vozeada por Guimarães Rosa em "Conversa de bois":

Eu acho que nós, bois - Dançador diz, com baba -, assim como os cachorros, as pedras, as árvores, somos pessoas soltas, com beiradas, começo e fim. O homem, não: o homem pode se ajuntar com as coisas, se encostar nelas, crescer, mudar de forma ou jeito... O homem tem partes mágicas... São as mãos... Eu sei... ${ }^{16}$.

${ }^{13}$ Benjamin Péret enuncia: "Ninguém, no entanto, pode permanecer estranho ao meio do qual provém. Quer sejamos esmagados por ele como por uma divindade, quer, feiticeiros, o ataquemos para dominá-lo, participamos dele plenamente. Assim é que Maria [Martins] confunde-se com o Brasil, e que este não seria, para nós, inteiramente o que é sem sua intervenção, pois ela o desvela para nós. De nenhum outro lugar do globo podia ela provir na medida em que nenhuma outra paragem, ao que parece, sugere no mesmo grau este inacabado que busca se imobilizar. Em nenhum outro lugar manifesta-se este ponto de interrogação sobre o próprio destino da terra no que ela tem de mais físico. É também este drama de uma gestação de infindável desenvolvimento que a obra de Maria reproduz e que ela tenta conduzir a um desenlace. Basta, com efeito, sobrevoar o curso do Amazonas para logo convencer-se de que os quatro elementos dos Antigos - longe de ter, no Brasil, adquirido suas qualidades próprias e trilhado cada um sua existência independente - permaneceram inextricavelmente misturados em uniões monstruosas e febris, cujo resultado se mantém imprevisível. A todo instante, por pouco que Maria se abandone, é o Deparei [...] com inacreditáveis Flóridas/Que misturavam às flores olhos de pantera com pele/ De homem! [...] de Arthur Rimbaud". PÉRET, Benjamin. Maria Martins: eternos começos do mundo. In: PONGE, Robert (Org.). Surrealismo e Novo Mundo. Porto Alegre: Editora da Universidade Federal do Rio Grande do Sul, 1999. P, 324.

${ }^{14}$ RICHTER, Gerhard. Atlas: photography, collages and sketches 1962-2006. Edited by Helmut Friedel. New York: D-A-P/Distributed Art Publishers, 2007. Outro documento desse "princípio-atlas" é a exposição registrada em DIDI-HUBERMAN, Georges. Atlas: ¿Cómo llevar el mundo a cuestas? Madrid: Museo Nacional Centro de Arte Reina Sofía, 2010. (catálogo).

${ }^{15}$ Cf. DIDI-HUBERMAN, Georges. Atlas, ou o gaio saber inquieto, op. cit., p. 43.

${ }^{16}$ ROSA, João Guimarães. Sagarana. 31. ed. Rio de Janeiro: Nova Fronteira, 1994, p, 326. 
Os bois-homens ou homens-bois de Empédocles - boustrophedon. Mãos postas sobre a mesa de dissecção. E é sintomático que no Expressionismo Alemão (um talvez epígono dos contrastes de luz-e-sombra da fase 'gótica' de Goya), a "reconstituição" que se faz da monstruosidade (no sentido Febrônio do Brasil) do califa Haroun Al-Haschid parta precisamente da falta de um braço. Refiro-me a "O gabinete das figuras de cera" ${ }^{17}$, filme mudo de Paul Leni em que o 'princípio-atlas' remonta figuras de cera de homens infames (também Ivan, o terrível, e Jack, o estripador). Pois o boneco de cera de Al-Haschid preservado no kabinett perdeu o seu braço esquerdo e é a partir da falta da mão que o personagem do Escritor remembra a vida - no sentido de rememoração - daquele maometano que ameaça a pax doméstica e conjugal do Padeiro (nos anos 1920, o sono e o sonho da razão europeia alimentavam as hipóteses de monstros: islamismo, czarismo e a ameaça de o todo volver à parte pelo evisceramento de Jack). "Errantes andavam braços soltos, sem ombros" (Empédocles): o monstro é semipleno.

Ao contrário, a mão chagada - i.é., a mão em excesso -, da figura central entre os fuzilados de "Três de maio em Madri" (1814), um óleo sobre tela de Francisco de Goya, ou a mão que escapa da holografia e denuncia a "invenção de Morel" (Bioy Casares) parecem indicar que o animal humano se dá a ver a partir do "manejo" (pois as mãos são demiúrgicas, como o pedem os dois bois de Rosa). O manejo: montagem.O monstro sem braço tem mãos imêmores. No reverso, a mão (a vigília da razão) manufatura o monstro, porque toma o corpo como objeto de dissecação e, a partir dos destroços / dos troços vários, cria encruzilhadas de história natural - muda-a de direção:

\footnotetext{
[...] as mãos do homem que trabalha directamente na matéria são mãos que estão atentas ao imprevisto, ao erro, e mesmo que pensem caminhar numa mesma direção (é urgente inventar-se um verbo para o acto das mãos que corresponda ao caminhar dos pés, porque as mãos também caminham como qualquer amassador sabe), cada percalço, cada erro, funciona como cruzamento, ou seja: como ponto onde é possível mudar de direcção. ${ }^{18}$
}

Esse breve excurso pelos procedimentos de remontagem dos monstra (mistura, iminência, inacabamento, adjunção, reconstituição) procura demonstrar que o díspar e o heteróclito são derivações da combinatória, e não da bizarria. Assim, a combinatória de Hebert Benítez a partir de Goya produz Unheimlich, porque "los monstruos viajan colmados de semen el deseo / de la gente [...]". No

17 LENI, Paul. O gabinete das figuras de cera (Das Wachen figuren kabinett), Alemanha, 1924.

${ }^{18}$ Cf. TAVARES, Gonçalo M. Atlas do corpo e da imaginação: teoria, fragmentos e imagens, op cit., p. 430. 
estranhamento da cesura do verso, essa erótica da travessia da "soleira" entre as espécies restitui toda uma fase empedocliana da evolução em que a distinção das qualidades era insuficiente e havia hiato nas carnações convulsas. Os corpos ainda 'à deriva', como os vegetais de Arcimboldo ou as folhas da copa que são pássaros na Árvore da Vida das culturas nórdicas.

Em contraste com o de Hebert Benítez, todo o pesadelo de Goya é mais estável: a fauna toma corpo, encosta e intimida, mas o homem que dorme jaz alienado e indene. E cabe aqui trazer à cena da leitura a hipótese de Benjamin, em "Rua de mão única" - "no asco por animais, a sensação dominante é o medo de, no contato, ser reconhecido por eles" ${ }^{19}$ - e lançá-la contra a figura do lince que arrosta, na Gravura 43, olhando-nos diretamente com dois olhos de luminescência fosforescente. Ele nos reconhece?

Porque ali avistado, o lince nos animaliza e, não havendo uma literatura divinatória/lírico-alegórica que dê vidência a essa figura - como as hepatoscopias assíria, etrusca e babilônica que, segundo Didi-Huberman, mediavam todas as antevisões do arúspice -, a imaginação silencia diante do lince (a figura do lince no sonho de Goya) como diante da antevisão de todo um devir humano-monstro. É um monstro a vir, em um "destino praticável", anódino, ou portátil, como prediz o poema: "morir dormir venir del monstruo es un destino practicable / en maletines logaritmos ensayos bolsillos bolsas con comidas".

Mas tornados à Gravura 43 ainda no Museu do Prado, vemos, com Carl Einstein (em "Aforismos metodológicos"), o quanto "o quadro é uma contração, uma parada dos processos psicológicos, uma defesa contra a fuga do tempo e, assim, uma defesa contra a morte. Poderíamos falar de uma concentração dos sonhos"20. E, não obstante, o tempo - tão fugado - quase torna ilegível a chave daquele terror setecentista, pois é contraído e parado, defendido da caducidade de tudo pela imobilidade do Museu. Então, "nadie sabe lo que ve", diz o poema. Assim, uma tomada rápida do conceito da transvisão (Carl Einstein) implica desativar o estereótipo do terrífico das figuras aziagas (morcego, coruja, corvo...) e, fora da estabilidade da vista e da metonímia "olhos de lince", é preciso recobrar a visão, antropológica e meta-psicológica, e - como as mãos sequer alcançam uma sombra dos astra -, nos reconhecermos "criaturas misturadas": uns filhos-monstro de mãe-matéria, todos. Por esse reconhecimento no asco, e como tudo se passa aqui no linde dos monstra, é preciso reabrir o quadro ao móbil da morte. Nesse gesto, pede-se de novo não saber o que se vê diante da vista, i.é., o produzir movimento.

${ }^{19}$ BENJAMIN, Walter. Rua de mão única. Tradução de Rubens Rodrigues Torres Filho e José Carlos Martin Barbosa. São Paulo: Brasiliense, 2011, p, 14.

20 EINSTEIN, Carl. Documents: 1929. Tradução de Takashi Wakamatsu. Desterro (Florianópolis): Cultura \& Barbárie, 2016, p, 7. 
Lendo a "amostragem do caos" no estilo heurístico de Goethe, Georges Didi-Huberman observa que a noção central do "gaio saber visual" do poeta (o seu atlas) é a de morfologia, pela qual cada um dos seus desenhos de flor, por exemplo, vê, ao mesmo tempo, "seu antes (o rebento, o broto) e seu depois (a ramificação)". ${ }^{21}$ Nessa condição diafórica de todo organismo, deve-se considerar em cada força e cada forma, subjacentes, sua pré-história (Vorgeschichte) e sua pós-história (Nachgeschichte), como o postula Walter Benjamin. Se 'depois' e 'antes' levam à diacronia (precursores/filiações), será mais fecundo tomar toda imagem in media res e na iminência de movimentar-se ${ }^{22}$.

Então, hipótese de Benítez, sonhos ${ }^{23}$ da razão produzem Goyas depois de Goya e, nesse movimento em onda, aquela visão dos monstruos que fervilham no poema pelo efeito da reiteração retira a gravura da condição estática, cultural e cultual da vista. Em termos mais diretos, o gesto semovente do poema movimenta a gravura cumulada de história (imobilizada pela história da arte). Ele ativa a força - e não a forma - da figura da gravura de Goya e, tomando-a em sua an-autonomia (segundo o termo e a lição de Rául Antelo), faz visão.

A visão em onda que reproduz, plagia, inova Goya, como intuíra D'Ors:

La [historia] de Goya amaneció hace dos siglos. Si su obra no ha dejado de sernos contemporánea, lo goyesco lo resulta más aún. A vera nuestra está. Pero, reconocemos mal todavía. [...] La tarea aguarda para completarse la colaboración de los espíritos lucidos a quienes no esclaviza las fórmulas consagradas y que saben que, también para el espíritu universal, "hay muchas auroras que no han nacido todavia". ${ }^{24}$

Tarefa por completar-se: devolver a Gravura 43 à mesa, ao fim, depois da imobilidade? Pequena máquina de leitura, o poema "Goya después de El Prado" parece "obnubilar" uma terceira imagem do pensamento, a da onda, para além da bipartição mão e monstro. Como o vimos, pela anáfora, esses monstruos vêm em ondas, monstros sobre monstros, e o poeta-montador manipula a sentença original e a rediz em muitas cópias sobre cópia, "como

${ }^{21}$ Cf. DIDI-HUBERMAN, Georges. Atlas, ou o gaio saber inquieto, op. cit., p. 153.

22 O filme $O$ moinho e a cruz (The mil and the cross, 2011), de Lech Majewski, pelo efeito de sua mise-en-scène, literalmente anima e movimenta as figuras do quadro A procissão para o Calvário (1564), de Pieter Brueghel, que narra a Paixão de Cristo durante a ocupação espanhola.

${ }^{23}$ Schopenhauer, em Die Welt $(I, \S 5)$, supõe o sonho como variação: "A vida e os sonhos são páginas de um mesmo livro. A leitura contínua chama-se vida real. Mas quando o tempo habitual de leitura (o dia) chega ao fim e vem a hora de descansar, então às vezes continuamos, fracamente, sem ordem e conexão, a folhear aqui e acolá algumas páginas: às vezes é uma página já lida, muitas outras vezes uma outra ainda desconhecida, mas sempre do mesmo livro". ABBAGNANO, Nicola. Dicionário de Filosofia. Tradução Alfredo Bosi; São Martins Fontes, 2012, p, 1088.

${ }^{24}$ D'ORS, Eugenio. Goya y lo goyesco: a la luz de la Historia de la Cultura. Valencia: B.Lopez Mezquida Editor, 1946, p, 56. 
loca estampida de palabras", isso porque "los sueños de la razón engendraron sueños", e, de um a outro verso, pratica a definição dicionarizada de onda: uma perturbação oscilante de alguma grandeza física no espaço e periódica no tempo. Ou seja, Benítez perturba Goya: ele depreende na aquatinta da gravura suas "ondas paradas de probabilidade"25 (evoco aqui a instalação homônima de Mira Schendel). Em seu procedimento de montagem, aciona as possibilidades combinatórias, fecunda trozos vários, e faz da gravura música.

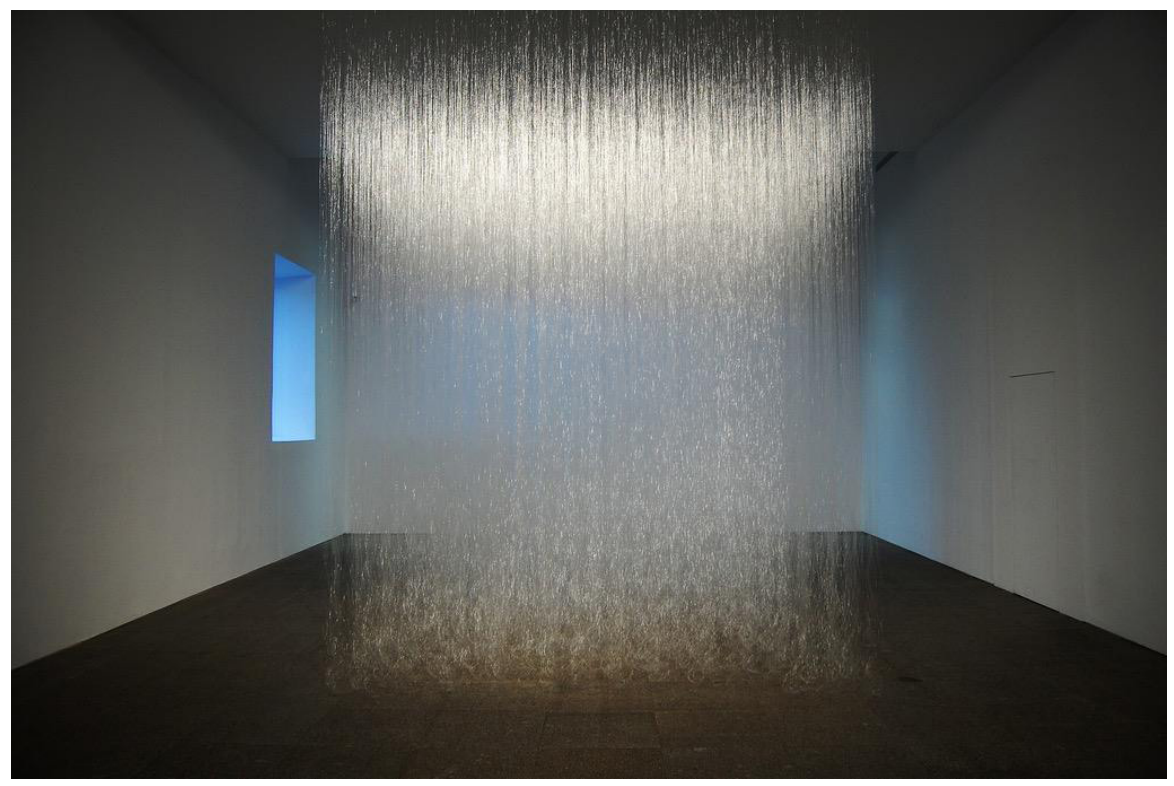

MIRA SCHENDEL - Ondas paradas de probabilidade - Antigo Testamento, Livro dos Reis I,19 (1969). Fios de nylon e texto sobre placa de acrílico, instalação, dimensões variáveis. Coleção Ada Schendel.

\section{Evoco o Pascal Quignard do Primeiro Tratado do ensaio "Ódio à música":}

Existe um fragmento de Pacuvius que enuncia o que interrompe a marcha martelante plurimilenar. Em 1823, J-B Levée o traduziu dessa maneira: “esse promontório cuja ponta avança no mar". Promontorium cujus lingua in altum projicit. Uma língua é aquilo pelo qual uma sociedade avança na natureza. A língua não prolonga propriamente dito o que é. Ela exterioriza. Ela introduz o fora numa plenitude. Introduz o retardo no imediato: é a música (ou a memória) e é por isto que mnèmosynè e musica são o mesmo. Logos insinua o dois no um. Em 520 depois de Cristo, o filósofo grego Damaskio, em Atenas - antes de ser expulso do império e exilado para a Pérsia pelos editos cristãos -, escrevia que cada logos era fundador de uma realeza de dissidência num universo contínuo. ${ }^{26}$

25 PÉRES-ORAMAS, Luís. León Ferrari e Mira Schendel: o alfabeto enfurecido. São Paulo: Cosac Naify; Nova York: Museu de Arte Moderna, 2010.

${ }^{26}$ QUIGNARD, Pascal. Ódio à música. Tradução de Ana Maria Scherer. Rio de Janeiro: Rocco, 1999, p, 19-20. 
Marcha martelante, o tempo. E o retardo no imediato: a memória com a música. No entanto, cada logos (cada sonho fecundado da razão) introduz uma dissidência/dissonância no contínuo da história (a $16^{\mathrm{a}}$. tese sobre a História de Walter Benjamin) e é viável conceber que, carregada de mnèmosynè no Museu do Prado, a Gravura 43 agora volva à musica. As ondas paradas da probabilidade ganham ritmo: não será esse o gesto de toda crítica?

Tendo visto mistura, iminência, inacabamento, adjunção, reconstituição, cabe ainda trazer à mesa o procedimento da seriação, a exemplo das fotografias do acervo digital do memorial das vítimas do Holocausto Yad Vashem, Jerusalém, que figuram, na apropriação da artista Leila Danziger, em "Navio de emigrantes" (o título que cita uma obra homônima de Lasar Segall), enquanto "Struma" - uma referência ao naufrágio de 1942 que vitimou 700 judeus na travessia entre a Romênia e a Turquia - figura toda a transumância como dobras de ondas:

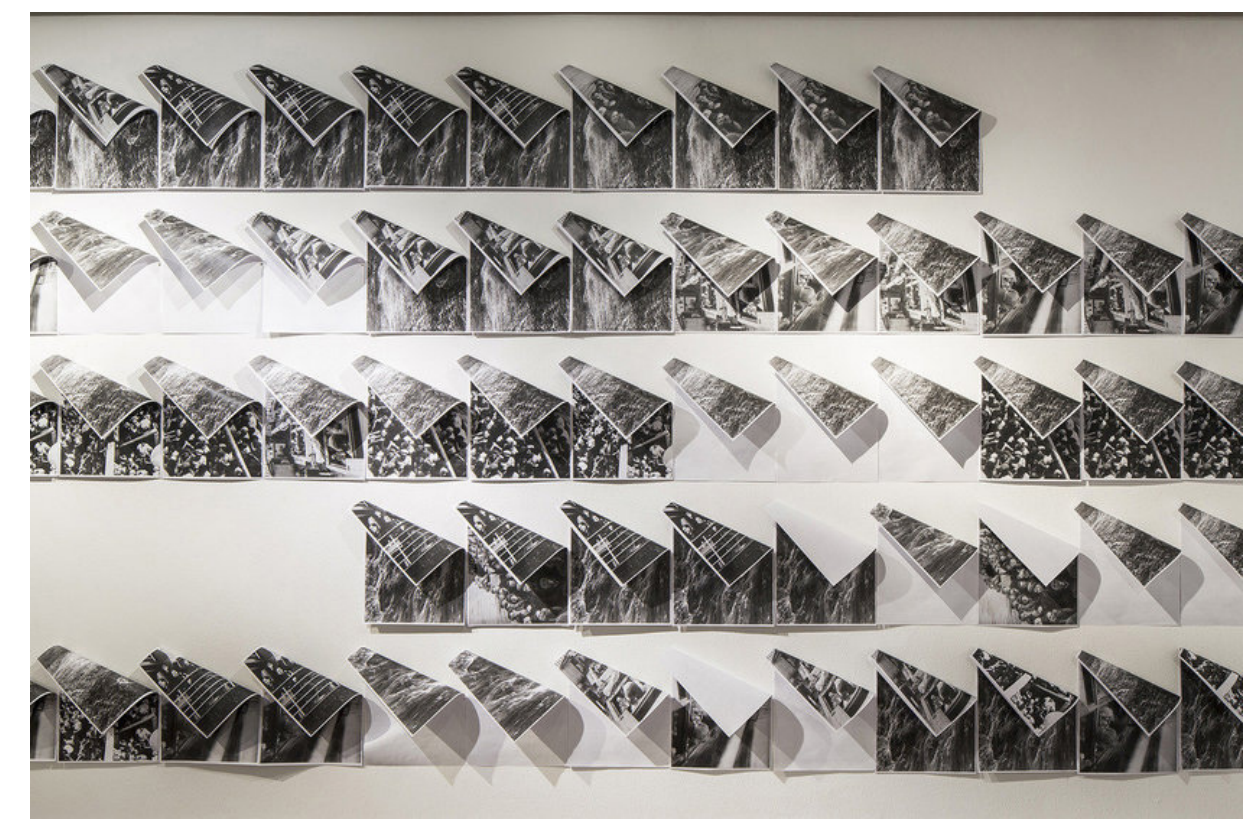

LEILA DANZIGER: "STRUMA" [2018] fotocópia (29,7x42cm), imãs, pregos; dimensões variáveis [detalhe].

Na estância final da leitura, o Jetztzeit (tempo de agora) irrompe com esse "Navio de emigrantes" 27 que - a exemplo da Kriegskartothek (1914-1918), de Aby Warburg - reúne os destroços (trozos vários de razón) dos arquivos para documentar as " $\mathrm{n}$ " probabilidades da deriva nos atravessamentos da

27 Exposição realizada na Caixa Cultural, São Paulo, de 15 de janeiro a 31 de março de 2019. 
geopolítica, ao mesmo tempo em que Leila Danziger pesquisa ${ }^{28}$ o autoiconoclasmo - história da autodestruição das imagens, como postula Peter Geimer -, porque, assevera, "constato que meu desejo de imagem é carregado sempre por esse desejo de apagamento, de ruína, de destruição da imagem - só há imagem em perigo".

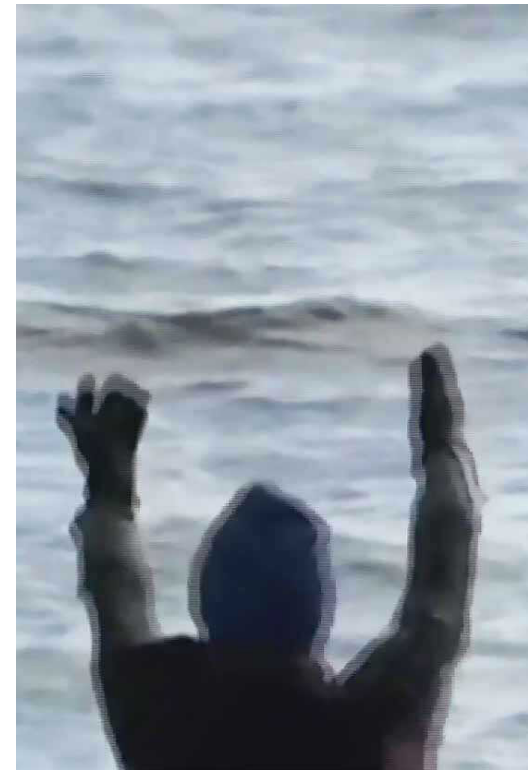

LEILA DANZIGER - Vídeo (frame)

Eis: a mão que atravessa o Oceano levanta-se em sinal de socorro e/ou de rendição, mas o monstro que é o mar a circunda sem pronunciar-se, e as ondas sumariam as levas de emigrantes fadados à desaparição. Nessa nova montagem (heteropias/heterocronias), o sonho de Goya produz Danziger, porque os sonhos da razão produzem desastres sem cessar.

E a semelhança mórfica engendra outra montagem: "o sonho da razia produz monstros"; e não é a Gravura 43 dos Caprichos uma "imagem do perigo" antes e depois do Prado, diuturnamente?

Finalmente, "Goya después de El Prado" traz à cena Sarajevo e Bagdá, outras cifras do desastre:

28 "Ao lidar com os documentos, pesquisados no Arquivo Nacional, desejei simplesmente abri-los, interrogar suas lacunas e espaçamentos, misturar as diferentes listas, lançá-las novamente no presente, numa grande arca de nomes e destinos, que quer abarcar não apenas os que aqui encontraram um porto, mas aqueles, muito mais numerosos, que o buscaram inutilmente. Compreendo as listas em si mesmas como embarcações, "pedaços de espaço flutuantes", como Foucault define os navios, heterotopias máximas, que abrigam os nomes dos passageiros e suas respectivas informações - idade, sexo, religião, profissão (inventadas, em sua maioria), estado civil, porto de procedência, último endereço no país de origem, e destino". DANZIGER, Leila. Navio de emigrantes (catálogo). São Paulo: Caixa Cultural, 2019, p. 16. 
Sarajevo Bagdad Montevideo colorean

pesadillas

soportables unas más que otras tampoco el

monstruo se arrebata

malo o bueno o más o menos

es ha sido el padre nuestro ahora es hora de

revolear la culpa

la razón germina escuelas bombardeadas es un

preciso radio

de rengueras no es un lugar común

la razón no empolla al monstruo es uno

de ellos

trepan pesadillas padre

por qué me has hecho esto

¿cuántos litros de sangre pero litros

según cálculos exactos, en cuanto a propiedades

del impacto, es decir en virtud de sus tangibles

casuales el calibre, el blanco, la distancia

no metáforas de mares o de ríos litros

mensurables en botellas ordenadas con critérios

de la razón que autoriza al decimal que no

produce monstruos

visitan Sarajevo le dan color de sueño y agregan

otras cosas?

vuelvo a cantar un árbol,

flores, la inminencia

de la muerte, la vida

vuelvo, vuelvo a aquellas cosas

al senderito de hormigas

cerca del mar y cerca del cielo

es un retorno

a cantar como si pudiera

ser un retorno a cantar

es que

me topo con lenguaje

me topo únicamente con lenguaje de continuo

no veo

me vuelvo

ciego ciego

es al que lenguaje se le mete

como víbora

entre la ropa

y ya fue picado aunque se cure

del veneno

ya fue

picado ${ }^{29}$

${ }^{29}$ BENÍTEZ, Hebert. Goya después de El Prado, op. cit., p. 393-396. 
Nessa travessia, no decurso de dois séculos, a imagem do perigo no Museu do Prado confronta os caprichos do desastre no Mediterrâneo: a anomalia da razão produz destruição de mundo depois de destruição de mundo. 